\title{
El Estallido Social en Chile: ¿rumbo a un Nuevo Constitucionalismo?
}

\author{
Tereza Maria Spyer Dulci ${ }^{1}$ \\ https://orcid.org/0000-0003-3891-2577
}

\author{
Vania Alvarado Sadivia ${ }^{2}$ \\ https://orcid.org/0000-0003-1087-3422
}

'Programa de Posgrado en Integración Contemporánea de América Latina, Instituto Latinoamericano de Economía, Sociedad y Política, Universidad Federal de la Integración Latinoamericana, Foz do Iguaçú, PR, Brasil ${ }^{2}$ Programa de Posgrado en Integración Contemporánea de América Latina, Instituto Latinoamericano de Economía, Sociedad y Política, Universidad Federal de la Integración Latinoamericana, Foz do Iguaçú, PR, Brasil

\section{El Estallido Social en Chile: ¿rumbo a un Nuevo Constitucionalismo?}

Resumen: Este artículo presenta un estudio del Estallido Social chileno, un conjunto de movilizaciones sociales que irrumpieron en varias ciudades de este país desde octubre de 2019. Con duras críticas al modelo económico neoliberal, estas movilizaciones han denunciado la ilegitimidad de la constitución vigente, fruto de la dictadura civil-militar. Una de las demandas de mayor consenso fue la exigencia de una nueva constitución por medio de una Asamblea Constituyente. A partir de los marcos epistemológicos del pensamiento decolonial, identificamos los rasgos generales del Estallido Social, revisamos el panorama histórico chileno y su articulación entre el autoritarismo político y el neoliberalismo, bien como examinamos la Constitución de 1980,-los pilares fundamentales que anclaron el modelo pinochetista-y las perspectivas de una nueva Carta Constitucional dentro del marco del Nuevo Constitucionalismo Latinoamericano.

Palabras clave: Estado. Autoritarismo. Estallido Social. Chile. Nuevo Constitucionalismo Latinoamericano.

\section{Os protestos socias no Chile: rumo a um Novo Constitucionalismo?}

Resumo: Este artigo apresenta estudo sobre os protestos sociais chilenos, um conjunto de mobilizações que eclodiram em várias cidades deste país a partir de outubro de 2019. Com duras críticas ao modelo econômico neoliberal, essas mobilizações denunciaram a ilegitimidade da constituição atual, fruto da ditadura civil-militar. Uma das demandas com maior consenso foi a exigência de uma nova constituição por meio de uma Assembleia Constituinte. A partir dos marcos epistemológicos do pensamento decolonial, identificamos as características gerais dos protestos sociais, revisamos o panorama histórico chileno e a articulação entre o autoritarismo político e o neoliberalismo, bem como examinamos a Constituição de 1980 - os pilares fundamentais que ancoraram o modelo pinochetista - e as perspectivas de uma nova Carta Constitucional no marco do Novo Constitucionalismo Latino-Americano.

Palavras-Chave: Estado. Autoritarismo. Protestos Sociais. Chile. Novo Constitucionalismo Latino-americano.

\section{The Chilean Social Outbreak: towards a New Constitutionalism?}

Abstract: This article presents a study of the Chilean Social Outbreak, a set of social mobilizations that erupted in various cities of that country since October 2019. With harsh criticism of the neoliberal economic model, these mobilizations have denounced the illegitimacy of the current constitution, which is the result of the civil-military dictatorship. One of the claims

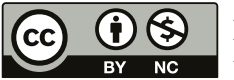

Este es un artículo publicado en acceso (Open Access) abierto bajo la licencia Creative Commons Attribution Non-Commercial, que permite su uso, distribución y reproducción en cualquier medio, sin restricciones siempre que sin fines comerciales y que el trabajo original sea debidamente citado. 
of greater consensus was the demand for a new constitution through a Constituent Assembly. Based on the epistemological framework of decolonial thought, our aim is to identify the general bearings of the Social Outbreak; review the Chilean historical panorama and its articulation between political authoritarianism and neoliberalism, as well as examine the 1980's Constitution -the mainstays that anchored the Pinochet model- and the potential perspectives of a new Constitution within the framework of the new Latin-American Constitutionalism.

Keywords: State. Authoritarianism. Social Outbreak. Chile. New Latin-American Constitutionalism.

Recebido em 05.05.2020. Aprovado em 03.08.2020. Revisado em 21.09.2020.

\section{Introducción}

El día 6 de octubre del 2019, el Metro de Santiago aumentó CL\$30 pesos el costo del pasaje, despertando con esto el malestar de los usuarios de este medio de transporte. Días después, estudiantes secundarios y universitarios comenzaron movimientos de desobediencia civil, saltando las manoplas y evadiendo el pago del pasaje. El gobierno de Sebastián Piñera (2018 -) respondió reforzando la seguridad y enviando a los Carabineros para controlar el ingreso en las estaciones, lo que generó un clima coercitivo y violento (Urrejola, 2019).

El 18 de octubre se generó una evasión masiva en casi la totalidad de estaciones, pero después de una serie de incendios y desmanes, se aumentó la represión policial y las manifestaciones se propagaron a otras ciudades. Como consecuencia, el presidente Piñera declaró Estado de Emergencia, restringiendo la libertad de locomoción y reunión. Por primera vez desde 1987, un presidente democráticamente electo promulgó toque de queda y puso a los militares en la calle. Como protesta, se realizaron cacerolazos en respuesta a la represión estatal (Urrejola, 2019).

Ante el aumento de las manifestaciones, el presidente expresó en cadena nacional que "Chile se encuentra en guerra contra un enemigo poderoso, implacable, que está dispuesto a usar la violencia sin ningún límite" (Andrews, 2019). A esto la población respondió con una gran movilización, cuya convocatoria, en la capital, superó al millón de personas. Es importante subrayar que según una encuesta ciudadana realizada a un mes de iniciadas las manifestaciones, el 83\% de la población las aprobaba y consideraba que las demandas fundamentales eran: pensiones por retiro, salud, desigualdad, delincuencia y educación (Activa Research, 2019).

El día 15 de noviembre del 2019, diversos representantes, tanto del oficialismo como de la oposición, firmaron el "Acuerdo por la paz y la Nueva Constitución" que buscó agilizar el proceso de elaboración de una nueva Carta Constitucional. En este se estableció que el 26 de abril del 2020 los chilenos podrían participar de un plebiscito para votar por el "apruebo" o "rechazo" de la realización de una Asamblea Constituyente, así como - en caso de ser aprobada - por la composición de la misma entre una "convención mixta", conformada por un 70\% de parlamentarios y un 30\% de civiles, o por una "convención constitucional", donde el 100\% de los participantes deberán ser electos democráticamente. Se presuponía que tal acto apaciguaría las manifestaciones, pero por el contrario logró avivarlas, debido a que el documento no contemplaba - caso ganase el "apruebo" -, la paridad de género, participación de pueblos indígenas y representantes de la comunidad civil, peticiones importantes para los manifestantes (Urrejola, 2019).

La renovación constitucional es un tema que representa un ajuste de cuentas con las herencias dejadas por la dictadura cívico-militar (1973-1990), ya que Chile es el único país de los que padecieron regímenes autoritarios del mundo cuya transición democrática mantuvo una institucionalidad dictatorial (Garretón, 2016). La Constitución de 1980 perdura con enclaves autoritarios que paradójicamente permanecieron vigentes en el período pos-redemocratización, en especial durante los gobiernos concertacionistas de centro-izquierda que, acoplándose al proyecto neoliberal, dejaron de lado las responsabilidades sociales del Estado y, protegidos por la Carta Constitucional, auspiciaron a los sectores privados (Atria, 2013).

Es este contexto que configura la génesis del Estallido Social que vive Chile actualmente. Una vez que la demanda por una nueva constitución democrática está apoyada en exigencias tales como la paridad de género, participación de pueblos indígenas y representantes de la comunidad civil, bien como la naturaleza como sujeto de derechos, asumimos que el pensamiento decolonial es pertinente para reflexionar acerca de la posibilidad de que la nueva constitución chilena pueda ser construida en el marco del Nuevo Constitucionalismo 
Latinoamericano que, al procurar incluir sujetos y colectivos históricamente excluidos y marginados, además de la naturaleza, busca romper con el modelo hegemónico neoliberal (Walsh, 2008).

De este modo, nuestro análisis está basado en los marcos epistemológicos del pensamiento decolonial, el cual parte de la premisa de que existe un patrón de poder colonial/moderno/eurocentrado/capitalista, fundado a partir de la construcción social del concepto de raza, que generó un modelo de estratificación fundamentado en la blanquitud, responsable por la desigualdad estructural de nuestra región (Castro-Gómez, Grosfoguel, 2007; Grosfoguel, Mignolo, 2008).

Así, en este artículo buscamos realizar un estudio preliminar, que en un primer apartado, identifique los rasgos generales del Estallido Social. En seguida, revisamos el panorama histórico chileno para destacar la articulación entre el autoritarismo político y el neoliberalismo en Chile. A continuación, examinamos la Constitución de 1980 que impuso el modelo neoliberal vigente y las perspectivas de la nueva Carta Constitucional dentro del marco del Nuevo Constitucionalismo Latinoamericano. Finalmente, presentamos algunas consideraciones finales sobre el tema.

\section{“¿Chile despertó!”}

Desde el 18 de octubre de 2019, Chile se vio colmado de protestas sociales masivas. Lo que primero significó un malestar por el aumento del pasaje del metro y la violencia del aparato estatal, transmutó a un malestar general dirigido a todo un sistema y clase política que fue heredado de la dictadura civil-militar y mantenido en los posteriores 30 años de democracia. Como bien resalta Gabriel Salazar: "Solo faltaba una chispa (cualquier chispa) que, crispando la piel de los adolescentes de Chile, que vienen mostrando más sensibilidad histórica e irritabilidad política que cualquier otro sector de la sociedad, hiciera estallar todo" (Salazar, 2019).

Cabe señalar que la expresión Estallido Social fue bautizada por los medios de comunicación en octubre de 2019 e incorporada después por la sociedad chilena. Según Mario Garcés (2019, p. 8): "Un estallido social es un acto multifacético de alteración del orden preestablecido que congrega a diversos actores, con sus propias dinámicas, que se sabe de antemano que tiene principio y fin, y que en muchos casos representa una "oportunidad" para hacer justicia por vía práctica [...]".

En estos conturbados meses, Chile pasa de ser un oasis sudamericano para el mercado internacional, a un espacio asolado por la rabia y el resentimiento contenidos por una "receta social" que remite a la dictadura. A partir de este momento, se pudo observar a un mandatario que parecía dislocado de su liderazgo y que anunciaba medidas sociales y cambios de gabinete junto con arreglos cosméticos, que no lograban aplacar el descontento ciudadano. Al completar los 15 días del Estado de Emergencia, el gobierno convocó al Consejo de Seguridad Nacional para buscar endurecer las penas contra quienes denominaba como "delincuentes que atentan contra la normalidad y la paz social" (Urrejola, 2019, p. 1).

Pero era esa "normalidad" la que se deseaba dejar atrás, ya que el miedo a que nada cambie es igual o mayor a que la violencia se vuelva crónica. Cabe destacar que los medios y organismos internacionales han denunciado sistemáticamente el uso desmedido de la fuerza por parte de carabineros, donde las marchas pacíficas - en su gran mayoría - fueron fragmentadas por lacrimógenas y carros lanza aguas, que contenían otros productos químicos, como soda cáustica. En respuesta, la Comisión de Derechos Humanos de las Naciones Unidas, Amnistía Internacional, Human Rights Watch y el Instituto Nacional de Derechos Humanos solicitaron prohibir los disparos cuya distancia represente un riesgo para la vida (Garcés, 2019).

Cuando el gobierno creía que las manifestaciones estaban cesando, un colectivo feminista e interdisciplinar llamado "Las Tesis", el día 25 de noviembre, inspirándose en la antropóloga argentina Rita Segato, entonó la cantata "un violador en tu camino". Esta performance, basada en los estudios de género de rasgo decolonial, puso nuevamente en la mira las manifestaciones chilenas, con una repercusión importante a nivel internacional, incluso con repetición de performances en otros países (Las Tesis, 2019).

Es interesante destacar también que durante el estallido, se ha replicado la remoción de estatuas que resaltan a invasores, colonizadores y genocidas. Estas fueron sustituidas por bustos de indígenas, lo que ha llevado el debate a otro nivel, al de resignificar y decolonizar la historia oficial y revalorizar una historia desde abajo, subterránea, que respete y realce la importancia de estos pueblos, y que entienda que estos deben tener voz en un proceso constituyente (Villanueva, Castillo, Vidaurrazaga, Cabieses y Poblete, 2019; Walsh, 2008). 
Desde el inicio del Estallido Social, los viernes se consumaron como el momento cúspide de las manifestaciones a nivel nacional. No obstante, entre los meses de enero y febrero de 2020, se decía irónicamente que la "revolución se había tomado vacaciones", debido a la disminución de marchas y manifestaciones. Aunque en realidad, se estaban preparando para una nueva oleada, que comenzó durante las primeras semanas de marzo, con el "súper lunes" (primera marcha de marzo) y la Marcha Internacional de la Mujer, el día 8 de marzo, que marcó una presencia histórica de manifestantes en las calles. A esto se sumaron las protestas lideradas por secundarios, el día 11 del mismo mes, contra Piñera, fecha en el que el mandatario cumplió sus dos primeros años de gobierno (Bustos, 2020).

Sin embargo, el 18 de marzo, todas las previsiones de la segunda etapa del estallido se derrumbaron ya que, debido a la contingencia de pandemia internacional por el Covid-19, el gobierno decretó Estado Excepcional de Catástrofe, cuyas atribuciones permiten la restricción de locomoción y reunión, por lo que las marchas, protestas y manifestaciones se vieron reducidas en su totalidad y el plebiscito se reagendó para el día 25 de octubre de 2020. Con todo, esta nueva crisis ha mostrado también, tal vez con más fuerza, los problemas estructurales que desataron el estallido del año anterior: "la precarización de los pobres, desigualdad social extrema, pensiones miserables, débiles sistemas de salud y de educación pública, etc." (Garcés, 2020). Se debe considerar también que:

\begin{abstract}
La actual crisis sanitaria, en su desarrollo, recolocará todos los problemas que instaló el Estallido Social como la necesidad de cambios económicos, sociales y políticos, que harán más urgente el cambio constitucional. En este sentido, vivimos un tiempo de tensión y de latencia ciudadana. Tensión, en el sentido que una deficiente administración de la crisis sanitaria podría desencadenar una aguda crispación y movilizaciones populares espontáneas; de latencia, en el sentido que nada de lo que se denunció durante el Estallido Social está resuelto y que la crisis sobre la crisis no niega, sino que redefine los nuevos derroteros que tomarán las luchas por venir (Garcés, 2020).
\end{abstract}

Hasta el momento, el aparato del Estado, en respuesta al Estallido Social, ha sido responsable de más de 34 muertos, de los cuales 8 fueron calcinados; 460 personas con pérdida de visión por balines y perdigones, 500 mujeres y niñas violentadas sexualmente, 7.000 personas heridas, 22.000 personas detenidas y 1.080 denuncias realizadas al Instituto Nacional de Derechos Humanos por torturas y crímenes de lesa humanidad (Instituto Nacional de Derechos Humanos, 2020).

El gobierno de Piñera cierra los primeros seis meses de estallido, y su segundo año presidencial, con el tercer cambio de gabinete, un 65\% de desaprobación, después de haber alcanzado un $84 \%$ en diciembre (Plaza Pública, 2020); dos acusaciones constitucionales, una rechazada contra el presidente Piñera y una aprobada para su ex ministro del interior Andrés Chadwick, considerándolo responsable político por las violaciones a los DD.HH (Villanueva, Castillo, Vidaurrazaga, Cabieses y Poblete, 2019) y un informe de la Oficina del Alto Comisionado de Derechos Humanos de las Naciones Unidas, encabezada por la ex presidenta Michelle Bachelet, que planteó la existencia de graves violaciones a los DD.HH, uso excesivo o innecesario de la fuerza, tortura, violencia sexual y detenciones arbitrarias (Alto Comisionado de Derechos Humanos de las Naciones Unidas, 2019). Todo lo mencionado nos llama a tener en cuenta que los antecedentes a estos conflictos son más profundos y remiten a hechos históricos-estructurales que marcan un antes y un después en la historia reciente de Chile.

\title{
“No es 1973, es 2019!”
}

En un escenario bipolar de Guerra Fría, en el que las grandes potencias se disputaban por obtener el apoyo de países menores, Chile era el primer país de la región en elegir a un presidente socialista. Después de tres intenciones fallidas de candidatura a la presidencia (1952, 1958 y 1964), Salvador Allende y el conglomerado de partidos de izquierda denominado Unidad Popular, consiguen ganar las elecciones de 1970. Dicho gobierno (1970-1973) buscaba representar la "vía chilena al socialismo", con la implementación de proyectos como la nacionalización del cobre, reforma agraria, estatización de sectores claves para la economía, ampliación de programas sociales, entre otros (Pinto et al., 2005). 
Pero desde sus inicios, debió convivir con una gran oposición. Tanto los gremios empresariales, los medios de comunicación, camioneros y grupos conservadores, boicotearon su ejercicio presidencial. A esto se le sumó el soporte y financiamiento estadounidense de la Agencia Nacional de Inteligencia, que impulsó la convergencia de las Fuerzas Armadas: Marina, Aeronáutica, Ejército y Carabineros, quienes encabezados por el general Augusto Pinochet, organizaron y ejecutaron un golpe de estado contra Allende el 11 de septiembre de 1973 (Correa et al., 2001).

Pinochet estableció una dictadura civil-militar que provocó un quiebre democrático y mantuvo el control social basándose en una "cultura del terror" - proceso que resultó en una violencia inédita en la historia nacional-; subordinó al poder militar la Constitución de 1925; acabó con programas sociales; persiguió minorías étnicas; censuró los medios de comunicación y prohibió cualquier ejercicio político. Estas medidas solo empeoran en 1975, con el llamado "milagro chileno", que se basaba en las premisas de los Chicago boys, cuyo fin era la instauración del neoliberalismo en el país, y que abrió un precedente para la aplicación de este modelo en los demás países de América Latina (Moulian, 2002).

El año de 1978 marcó uno de los más críticos para el régimen de Pinochet: por un lado fue publicada la Ley de Amnistía, que concedió el perdón a los colaboradores de la dictadura entre 1973 y 1978, eximiéndolos de su responsabilidad penal, civil y militar por violaciones a los Derechos Humanos, y por el otro lado, los Estados Unidos - que habían apoyado la instauración de la dictadura -, se volvían uno de sus principales rivales, debido principalmente al atentado contra Orlando Letelier en suelo estadounidense. Por lo que el presidente Jimmy Carter y diversos organismos internacionales exigieron mayores libertades civiles en Chile y en los demás países de la región, además de terminar con la censura de los medios y represión a la oposición (Correa et al., 2001).

Este hecho alertó a Pinochet, quién en respuesta a la presión internacional, llamó a un plebiscito en 1980, que, a pesar de ser cuestionable, sirvió como legitimación de un nuevo texto constitucional que fue ratificado en 1981, cuando Pinochet asumió como Presidente de la República con una duración de 8 años. Sin embargo, a mediados de los ochenta, las reformas dejaron de ser milagrosas. Disminuyeron las inversiones extranjeras, aumentaron los desempleos y se levantaron organizaciones de guerrillas armadas, movimientos sociales, exiliados e intelectuales que formaron un frente de oposición. Además, en 1988 se cumplió el tiempo estipulado de la presidencia, por lo que se llamó nuevamente a un plebiscito (Nogueira, 2008).

Contra todo pronóstico, en el plebiscito Pinochet fue derrotado, lo que llevó a elecciones presidenciales y parlamentarias, dando paso a la controversial "transición consentida", liderada por la Concertación de Partidos de Izquierda. Después de vencer las elecciones, esta coalición dominó la política chilena por los próximos veinte años. La hegemonía concertacionista fue quebrada con la victoria de la coalición de derecha bajo la Alianza por Chile, que llevó a Piñera a la presidencia (2010-2014). Aunque la Concertación volvió al poder nuevamente con Bachelet (2014-2018), Piñera regresó para un segundo mandato el año 2018 (Moulian, 2002).

\section{¡No son 30 pesos, son 30 años!”}

Chile se sitúa a nivel mundial como una de las pocas democracias que no han definido su marco constitucional mediante un proceso libre y abierto. Aspecto que se remite también a las Constituciones de 1833 y 1925. Por lo que "la idea de promover una asamblea constituyente representativa del conjunto de la ciudadanía ha estado prácticamente ausente del diseño constitucional” (Fuentes, 2010, p. 9). En ese sentido, ningún texto constitucional ha sido producto del debate político, rodeado del marco democrático, sino de la violencia, de la intervención de las fuerzas armadas y de la existencia de "vencedores y vencidos" (Valdivia, 2010, p. 131).

Así, en octubre de 1980 fue promulgada la nueva Constitución. En su elaboración intervinieron la Comisión Ortúzar, el Consejo de Estado, la Junta de Gobierno integrada por los altos mandos de las Fuerzas Armadas y el Director General de Carabineros. Estas entidades fueron las responsables de definir las categorías políticas e ideológicas que sustentaron la Carta Fundamental hasta la actualidad (Fuentes, 2010).

Para Fernando Atria (2010, p. 171-172) "la Constitución no es un texto: es una decisión. Y no cualquier decisión, sino la decisión fundamental, sobre forma y modo de existencia de una comunidad política". En este sentido, los artículos, capítulos y disposiciones transitorias de la Carta Constitucional que emerge en la 
dictadura, definen los pilares del proyecto dictatorial: Constitución política; Plan Laboral; Subcontratación; Sistemas de Administradoras de Fondos de Pensiones; Sistema Tributario; Privatización de la Educación; Sistema de Salud; Sistema Bancario; Fomento Forestal; Desnacionalización del Cobre y Privatización del Agua (Fundación Sol, 2011).

En definitiva, la Carta Constitucional consagró un papel subsidiario del Estado a la economía, entregó a las Fuerzas Armadas un rol tutelar de la democracia y concibió el derecho a la propiedad privada. Según Couso y Coddou (2010, p. 196), el capítulo III de la Constitución "De los derechos y deberes constitucionales", deja en evidencia una protección al derecho de la propiedad privada, la cual contrasta con el mediocre o nulo reconocimiento de importantes derechos como: educación, huelga, vivienda y uso de recursos naturales básicos como el agua. Para Manuel Garretón (2016), el texto que consagró un orden socioeconómico y político en medio de una crisis de legitimidad, tiene a su vez, una ilegitimidad de origen, ya que fue impuesta:

[...] a través de la fuerza y coacción, violando y eliminando las normas precedentes, y valorativa, en la medida que no procede de un consenso o pacto social lindante ni prevé las posibilidades de cambio sustantivo, pero también instrumental, porque esa instrumentalidad es puramente adaptativa por parte de la mayoría de los actores de la sociedad y en los últimos años ha provocado múltiples reacciones de rechazo (Garretón, 2016, p. 80-81).

Ante lo mencionado, Atria (2010, p. 172) agrega que si se sugiere precisamente que el problema está en el origen, no importa cuántas reformas haya sufrido, "su origen lo contamina todo". Por ello, las reformas al texto no solucionan la problemática de la ilegitimidad, y no brindan los resultados esperados.

En los años 1989 y 2005 se produjeron las principales reformas constitucionales. El primero, producto de la negociación entre la dictadura civil-militar y la entonces oposición política y que fue refrendado en el plebiscito de 1988 y el segundo, resultado de un acuerdo político entre los partidos de la Concertación y la oposición de derecha, encabezado principalmente por la Alianza por Chile, durante la presidencia de Ricardo Lagos (2000-2006) (Fuentes, 2010, p. 9).

Es importante destacar que el debate constitucional del año 2005 era llamado en ese entonces de "la gran reforma", pero resultó que las elites concertacionista y extraparlamentaria se mostraron divididas frente a la posibilidad de promover una nueva Constitución. Tal hecho deja en evidencia que el proceso "desde arriba" no buscaba modificar las desigualdades estructurales, nomás reformar el sistema. Este ciclo modificó: la distribución del Senado, eliminó a los senadores vitalicios y designados y redujo el período presidencial de seis a cuatro años sin reelección inmediata (Saldaña, 2010).

Los enclaves autoritarios eliminados son innegablemente importantes, pero nuevamente la ilegitimidad de origen es la que hizo fracasar la Constitución del 2005, por lo que "[...] todo lo que sea aprobado mediante esas formas será imposible de reconocer como voluntad del pueblo y perpetuará el problema constitucional" (Atria, 2010, p. 179). Sin embargo, no debería de sorprender en demasía, ya que las reformas fueron "[...] lo que los herederos políticos de la dictadura estuvieron dispuestos a conceder" (Couso y Coddou, 2010, p. 194).

De esta forma, los debates constitucionales posteriores a 2005 colocaron a tono temas como: descentralización y gobierno regional, régimen político, control horizontal de poderes, inclusión de la sociedad en mecanismos de decisión y derechos económico-sociales, entre otros. Pero aún existen temas que son el centro de las discusiones desde el proceso de transición a la democracia: la reforma de Leyes Orgánicas Constitucionales, el sistema electoral y el Tribunal Constitucional (Fuentes, 2010).

Un necesario énfasis debe hacerse entonces a una de las mayores olas de protestas desde el final de la dictadura. Tuvo sus inicios el año 2006 y alcanzó su auge el año 2011. La llamada "Revolución Pingüina" fue articulada por una generación de estudiantes secundarios, que no creció en dictadura: los "hijos de la democracia" (Cañas, 2016). La principal demanda del movimiento era la derogación efectiva de la Ley Orgánica Constitucional de Enseñanza, promulgada el año 1990, y que entregaba al Estado la facultad de resguardar la "libertad de enseñanza", entendida, es claro, en concepciones liberales. Se debe enfatizar la importancia del perfil homogeneizador del movimiento, ya que desde el año 2011 adopta un carácter "intensivo y extensivo", llevando la protesta hacia otros sectores, que sumaron sus demandas sobre la actualidad del pasado en la estructura social, política y económica de Chile (Cañas, 2016, p. 122-123). 
Es importante destacar que el año 2015, la presidenta Bachelet anunció un proceso constituyente, considerado "histórico", que proponía una estrategia educacional y participativa, el cual concluiría con un proyecto ciudadano a ratificarse en el Congreso el año 2017 para en último lugar definir un mecanismo o instancia para la elaboración del nuevo texto constitucional, siendo posible una convención mixta, una asamblea constituyente o un plebiscito que definiera las tres opciones anteriores (Garretón, 2016).

Queda en evidencia, con las manifestaciones y la crisis social que Chile vive en la actualidad, que lo propuesto por Bachelet no llegó a buen puerto, y quedó, como muchos otros promisorios proyectos, archivados en algún cajón del Congreso. Ante lo mencionado, Verónica Valdivia señala que "históricamente la clase dirigente chilena se ufanó de haber construido un país estable y en orden. Sin embargo, su relación con la democracia fue tensa, alejándose de sus concepciones muy tempranamente" (Valdivia, 2010, p. 144).

Se debe considerar que los gobiernos concertacionistas de centro-izquierda fueron los victoriosos del plebiscito que derrocó la dictadura civil-militar y que contó con una ventana de 20 años de democracia para modificar la constitución pinochetista de 1980. Pero, en lugar de eso, no cambiaron los problemas estructurales. En este sentido, las interrogantes son: ¿Por qué líderes democráticamente electos, de sesgo progresista, retuvieron una constitución de dictadores? y ¿El Estallido Social será capaz de generar una nueva constitución realmente contrahegemónica?

Lo que ahora podemos afirmar es que desde el Estallido Social, la población chilena -que para el gobierno carece de organización e petitorios claros- comenzó a organizarse por fuera de lo que denominan "banderas políticas". Debido, entre otras cosas, a que "Chile está experimentando una ruptura en la relación clásica entre política institucional: partidos, Congreso, Ejecutivo y otras instituciones y la sociedad civil" (Garretón, 2016, p. 82).

\section{“Hasta que la dignidad se haga costumbre!”}

El Nuevo Constitucionalismo Latinoamericano es un conjunto de constituciones que se desarrollan en América Latina a partir de los años 90 y se caracteriza por cimentarse en exigencias populares, que conlleven procesos amplios, plurales, participativos y democráticos. Entendiendo esto como una "forma mediante la cual la voluntad constituyente es trasladada a la voluntad constituida" (Salmorán, 2016, p. 2).

Esta corriente se basa en la generación de nuevas Cartas Fundamentales mediante Asambleas Constituyentes. Ecuador (2008) y Bolivia (2009) son los ejemplos más recientes y que trajeron a tono los conceptos de: "plurinacionalidad", "buen vivir" y el entendimiento de "la naturaleza como sujeto de derechos". Estas constituciones son fruto de luchas de mayorías indígenas y campesinas, desde donde nace un pensamiento político que invoca a quienes carecen de lugar en las altas esferas de poder. Para Catherine Walsh (2008, p. 147) buscan:

[...] cuestionar y transgredir los modelos y las prácticas fundadoras del Estado y los modelos y prácticas más recientes de la política neoliberal, incluyendo el bienestar neoliberal cuyo enfoque es el individuo y el individualismo alienante de tener, lo que hace cada vez más fragmentada y débil la relación social y de sociedad.

Lo recién mencionado llama nuestra atención para reflexionar sobre los pilares de esta corriente que podrían considerarse, a la hora de situarnos en un ejercicio democrático para Chile. Se debe mencionar además, que el Estallido Social llevó a miles de personas a formar cabildos autoconvocados, tanto a nivel regional, desde Arica a Puerto Williams, como a nivel internacional, en países como: Argentina, Francia, México y Perú, donde chilenos radicados en dichos lugares, ejercitaron su derecho cívico a repensar el Chile que quieren (Unidad Social, 2019). Según Ana Zazo-Moratalla (2019, p. 1): "los cabildos temáticos deliberan sobre cuestiones concretas como el género, el medio ambiente, el patrimonio o la soberanía alimentaria, en aras de generar una nueva conciencia ciudadana y de sintetizar los puntos sustanciales que deberían ser recogidos en una nueva constitución".

Así, el Chile de hoy cuenta con un movimiento social y político mucho más extenso que décadas atrás, en el cual era posible estratificar entre: ambientalistas, camioneros, profesores, etc. Fue precisamente el Estallido Social, que logró congregar a todos ellos, y tantos otros, con demandas comunes que desembocan en una nueva 
constitución mediante una Asamblea Constituyente. La Mesa de Unidad Social - colectivo conformado por cerca de 100 organizaciones ciudadanas, gremiales y sindicales -, recibió más de 450 actas de los cabildos ciudadanos, documentos que destacan las principales demandas, entre ellas: Asamblea Constituyente; Protección del medio ambiente; Nacionalización de recursos naturales; Igualdad de género y enfoque feminista para las políticas públicas y Democracia participativa y vinculante (Unidad Social, 2019).

Históricamente la participación de las mujeres en cargos de elección popular ha estado limitada por la división sexual del trabajo y los roles de género tradicionalmente paternalistas. En los que las mujeres están mayormente restringidas al espacio privado y los hombres a lo público. Pero con el Estallido Social, fueron diversos movimientos feministas y de disidencias que, marcando pauta con "Las Tesis", el "8M" y otras manifestaciones, lograron presionar al legislativo, para que finalmente el 4 de marzo del 2020, sea aprobada la paridad de género en el Congreso. Mediante la frase "nunca más sin nosotras", enfatizaron los vacíos de su ejercicio cívico y político y que no aceptarán más estar al margen de la historia, ni de las decisiones políticas, económicas y sociales (Condemarín, 2020).

Otra cuestión-clave del proceso constituyente, se debe a la relación que tiene el Estado con la población indígena, y la falta de comprensión e interés hacia las diversas cosmovisiones de sus 9 pueblos reconocidos. Como también a las sistemáticas políticas de reducción de tierras comunales y cultivables y el empobrecimiento histórico y cultural progresivo al que fueron sometidos. Esto se percibe, igualmente, en la nula consideración que se ha tenido para su participación en el proceso constituyente, cuya legislación, a pesar de presiones, ha sido dejada de lado, por un evidente racismo institucional (Ser.PE, 2019).

A propósito de lo anterior, se agrega el fortalecimiento del extractivismo en Chile en las últimas décadas, fruto de la privatización de los bienes comunes, que generó un fuerte incremento de la desigualdad. El ejemplo más paradigmático es la lucha contra la privatización del agua. Este es un tema considerado esencial por el "Cabildo por la Soberanía Socioambiental", que, a partir de un giro biocéntrico, busca combatir la privatización de los bienes comunes naturales y la destrucción del medio ambiente. Considerando la naturaleza como sujeto de derechos, demanda, entre otras cosas, la derogación del Código de Aguas, heredado de la dictadura (Modatima, 2020).

En definitiva, un nuevo texto constitucional debe hacerse cargo de un doble problema, por un lado, debe permitir el cambio del actual ordenamiento socio-económico y político por uno que sea legítimo, y al mismo tiempo, debe pensar en un modo de elaborarlo que se constituya como un hito para resolver la crisis estructural y orgánica entre política y sociedad (Garretón, 2016), considerando que las condiciones de partida, de dicho proceso, es un país que "[...] no solo tiene una de las declaraciones de derechos más regresivas de la región, sino que además preserva una organización del poder tan autoritaria como pocas" (Gargarella, 2020).

\section{Consideraciones finales}

Al contrario del sentido común construido por la retórica neoliberal, que defendió por décadas que Chile era el oasis sudamericano, en este país de gran desigualdad social - con uno de los costos de vida más altos en América del Sur - estalló una de las movilizaciones más contundentes de nuestra región. La lucha contra la desigualdad estructural chilena, fruto de una Carta Constitucional promulgada por la dictadura civil-militar de Pinochet, que sigue vigente después de más de 30 años, parece ser imparable.

Como tratamos de demostrar en este estudio preliminar, una vez que el proceso sigue en curso, el Estallido Social deviene de la crítica hacia la legitimidad del ordenamiento constitucional neoliberal y del sistema de democracia restringida, a la que la población respondió con una movilización general cuyas consignas generaron frases como: "no estamos en guerra", "nosotros tenemos ollas, ustedes metralletas", “iChile despertó!", “¡No es 1973, es 2019!", “¡No son 30 pesos, son 30 años!" o "hasta que la dignidad se haga costumbre".

Al buscar una ruptura con las formas autoritarias, la nueva constitución puede representar una apertura institucional a las demandas ciudadanas a través de una Carta Constitucional democrática, desde abajo, que podría ser la primera en la historia chilena. Igualmente, la nueva constitución podría simbolizar un marco no solo en la producción legal latinoamericana, al ir más allá de la concepción del Estado que jerarquiza a los pueblos, razas, culturas y modos de producción, sino que el derecho podría ser, en este caso, un instrumento 
para enfrentar la colonialidad, donde el subalterno sea partícipe en la producción del derecho, aunque esto no significa su efectividad, como es posible observar a partir de los casos ecuatoriano y boliviano.

\section{Referencias}

ACTIVA RESEARCH. (6 noviembre 2019). Pulso Ciudadano. Disponible en: https://www.activasite.com/wp-content/uploads/2020/01/524de-los-chilenos-creen-que-las-pensiones-son-el-principal-problema-del-pa\%C3\%ADs.pdf

ALTO COMISIONADO DE LAS NACIONES UNIDAS PARA LOS DERECHOS HUMANOS. (2019). Informe sobre la crisis en Chile describe múltiples violaciones de derechos humanos y hace un llamado a reformas. Ginebra. Disponible en: https://acnudh.org/ chile-informe-describe-multiples-violaciones-de-derechos-humanos-y-llama-a-reformas/

ANDREWS, J. P. (20 octubre 2019). Presidente Piñera: "Estamos en guerra contra un enemigo poderoso". La Tercera, Política, Gobierno, Piñera. Disponible en: https://www.latercera.com/politica/noticia/presidente-pinera-estamos-guerra-enemigo-poderoso/870658/ ATRIA, F. (2010). Participación y alienación política: el problema constitucional. In Fuentes, C. En nombre del pueblo: debate sobre el cambio constitucional en Chile (pp. 163-190). Santiago: Ediciones Boell Cono Sur.

ATRIA, F. (2013). La Constitución Tramposa. Chile: LOM Ediciones.

BUSTOS, A. (2019). "El grito de las que ya no están": la lucha contra los feminicidios en América Latina. Radio Universidad de Chile. Disponible en: https://radio.uchile.cl/2020/03/07/el-grito-de-las-que-ya-no-estan-la-lucha-contra-los-femicidios-en-america-latina/

CAÑAS, E. (2016). Movimiento estudiantil en Chile 2011: causas y características. Revista de Historia y Geografía, 34:109-134. https://doi.org/10.29344/07194145.34.357

CASTRO-GÓMEZ, S.; GROSFOGUEL, R. (2007). El giro decolonial: reflexiones para una diversidad epistémica más allá del capitalismo global. Colombia: Siglo del Hombre Editores.

CONDEMARÍN, A. (12 marzo 2020). Nunca más sin nosotras. El Mostrador, Noticias. Disponible en: https://www.elmostrador.cl/ noticias/opinion/2020/03/12/nunca-mas-sin-nosotras/

CORREA, S. et al. (2001). Historia del siglo XX chileno. Chile: Editorial Sudamericana.

COUSO, J y CODDOU, A. (2010). Las asignaturas pendientes de la reforma constitucional chilena. En nombre del pueblo. Debate sobre el cambio constitucional en Chile (p. 191-212). Chile: Salesianos Impresores S.A.

FUENTES, C. (2010). En nombre del pueblo. Debate sobre el cambio constitucional en Chile. Chile: Salesianos Impresores S.A.

FUNDACIÓN SOL. (2015). Los 11 pilares dictatoriales que sostienen el modelo económico-social. Disponible en: http://www. fundacionsol.cl/2015/09/la-violencia-estructural-y-cotidiana-a-42-anos-del-golpe-los-11-pilares-dictatoriales-que-todavia-sostienenel-modelo-economico-social/

GARCÉS, M. (2019). Octubre de 2019: el estallido social en el Chile neoliberal. EPES. Disponible en: http://www.epes.cl/2020/01/ conservatorio-con-el-historiador-mario-garces-estallido-social-en-el-chile-neoliberal/

GARCÉS, M. (2020). Crisis sobre la crisis: del estallido social a la emergencia del coronavirus. LOM. Disponible en: https://lom.cl/ blogs/blog/crisis-sobre-la-crisis-del-estallido-social-a-la-emergencia-del-coronavirus

GARGARELLA, R. (2020). Diez puntos sobre el cambio constitucional en Chile. Nueva Sociedad. Disponible en: https://nuso.org/ articulo/diez-puntos-sobre-el-cambio-constitucional-en-chile/

GARRETÓN, M. A. (2016). La crisis de la sociedad chilena, nueva Constitución y proceso constituyente. Revista Anales, Santiago, 7(10):77-92. Disponible en: https://revistas.uchile.cl/index.php/ANUC/article/download/43143/45099.

GROSFOGUEL, R.; MIGNOLO, W. (julio, diciembre 2008). Decolonial Interventions: A Brief Introduction. Tabula Rasa, Bogota, 9:29-38. Disponible en: http://www.scielo.org.co/scielo.php?script=sci_arttext\&pid=S1794-24892008000200003.

INSTITUTO NACIONAL DE DERECHOS HUMANOS. Reportes 2019-2020. Disponible en: https:// www.indh.cl/noticias/noticias-indh/ LAS TESIS (25 noviembre 2019). El violador eres tú. Chile.

MODATIMA (2020) Modatima Santiago avanza en el planteamiento de los desafíos socioambientales para una nueva constitución. Santiago. Disponible en: http://modatima.cl/2020/03/02/modatima-santiago-avanza-en-el-planteamiento-de-los-desafios-socioambientalespara-una-nueva-constitucion/\#more-2047

MOULIAN, T. (2002). Chile actual: anatomía de un mito. Chile: LOM Ediciones.

NOGUEIRA, H. (2008). La evolución político-constitucional de Chile 1976-2005. Estudios constitucionales, 6(2):325-370. Disponible en: https://dx.doi.org/10.4067/S0718-52002008000100011

PINTO, J. et al. (2005). Cuando hicimos historia. La experiencia de la Unidad Popular. (pp. 1-86). Chile: LOM Ediciones.

PLAZA PÚBLICA (2020). Aprobación presidencial. Disponible en: https://plazapublica.cl/encuestas/plaza-publica-cadem-encuestano-327/ 
SALAZAR, G. (2019). El "reventón social” en Chile. Una mirada histórica. Nueva Sociedad. Disponible en: https://nuso.org/articulo/ protestas-Chile-estudiantes-neoliberalismo/

SALDAÑA, J. (2010). Reformas constitucionales en el Chile democrático. In En nombre del pueblo: debate sobre el cambio constitucional en Chile. (pp. 85-112). Chile: Salesianos Impresores S.A.

SALMORÁN, G. (2016). Bolivia, Ecuador y Venezuela: ¿un nuevo constitucionalismo latinoamericano o nuevas autocracias plebiscitarias? G.Q., 16(2):1-23. Disponible en: https://www.academia.edu/34297400/Bolivia_Ecuador_y_Venezuela_un_nuevo_ constitucionalismo_latinoamericano_o_nuevas_autocracias_plebiscitarias

SER.PE. (29 noviembre 2019). Convención constituyente en Chile y participación de pueblos indígenas. Disponible en: http://www. noticiasser.pe/informe/convencion-constituyente-en-chile-y-participacion-de-pueblos-indigenas

UNIDAD SOCIAL. (2019). Cabildos autoconvocados abiertos. (Principales demandas). https://drive.google.com/file/ d/1BT6E6tca5AluwjFSSjmFg-h1-xSt2qt2/view.

URREJOLA, J. (2019). La cronología del estallido social de Chile. Deutsche Welle. Disponible en: https://www.dw.com/es/lacronolog\%C3\%ADa-del-estallido-social-de-chile/a-51407726

VALDIVIA, V. (2010). Estabilidad y Constitucionalismo: las sombras de la excepcionalidad chilena. En nombre del pueblo. Debate sobre el cambio constitucional en Chile. (pp. 131-154). Chile: Salesianos Impresores S.A.

VILlANUEVA, E., CASTILlO, J., VIDAURRAZAGA, I., CABIESES, M., POBLETE, C. (28 octubre 2019). Comentarios sobre la generalización de la protesta en Chile. De la evasión a la rebelión y al coronavirus. Le Monde Diplomatique, Chile. Disponible en: https://www.lemondediplomatique.cl/comentarios-sobre-la-generalizacion-de-la-protesta-en-chile-de-la-evasion-a-la.html

WALSH, C. (2008). Interculturalidad, plurinacionalidad y decolonialidad: las insurgencias político-epistémicas de refundar el Estado. Tabula Rasa, (9):131-152. Disponible en: http://www.scielo.org.co/scielo.php?script=sci_arttext\&pid=S1794-24892008000200009\&ln $\mathrm{g}=\mathrm{en} \& \mathrm{tlng}=\mathrm{es}$

ZAZO-MORATALLA, A. (noviembre 2019). Chile despertó, y se auto-organizó. Urbano, 22(40):4-9. https://doi.org/10.22320/071 83607.2019.22.40.00

\section{Tereza Maria Spyer Dulci}

tereza.spyer@unila.edu.br

Doutorado em História Social pela Universidade de São Paulo (USP)

Professora Adjunta da Universidade Federal da Integração Latino-Americana (UNILA)

\section{Vania Alvarado Saldivia}

vania.saldivia@unila.aluno.edu.br

Bacharelado em Relações Internacionais e Integração e Licenciatura em História pela Universidade Federal da Integração Latino-Americana (UNILA)

Mestranda em Integração Contemporânea da América Latina (ICAL/ UNILA)

\section{UNILA}

Avenida Silvio Américo Sasdelli, 1842 - Bairro Itaipu A, Edifício Comercial Lorivo Foz do Iguaçu - Paraná - Brasil

CEP: 85866-000

\author{
Agradecimentos \\ Este artículo es fruto de las discusiones realizadas en el \\ Posgrado en Integración Contemporánea de América Latina, de \\ la Universidad Federal de la Integración Latinoamericana, en \\ la línea de investigación "Cultura, Colonialidad/Decolonialidad \\ y Movimientos Sociales" y en el Grupo de Investigación \\ "Descolonizando las Relaciones Internacionales". Agradecemos \\ igualmente la lectura perspicaz y las sugerencias del profesor \\ Alfredo Nava Sánchez, de la Universidad Federal de São João \\ del-Rei (UFSJ).
}

\author{
Agência financiadora \\ No se aplica. \\ Contribuições das autoras \\ No se aplica. \\ Aprovação por Comitê de Ética e consentimento para \\ participação \\ No se aplica. \\ Consentimento para publicação \\ Autorizamos la publicación de este artículo. \\ Conflito de interesses \\ No hay conflicto de intereses.
}

